\title{
EFFECTIVENESS OF 0.2\% ROPIVACAINE OR 0.2 \% BUPIVACAINE DURING ULTRASOUND GUIDED AMBULATORY INTERSCALENE PLEXUS BLOCK FOR FROZEN SHOULDER MOBILIZATION
}

\author{
Naveen Chandru Anguchamy1, Vijayakumar Natarajan², Kamalakannan Manian³ \\ ${ }_{1}^{1}$ Assistant Professor, Department of Anaesthesia, KFMSR, Coimbatore, Tamilnadu, India. \\ ${ }^{2}$ Senior Resident, Department of Anaesthesia, KFMSR, Coimbatore, Tamilnadu, India. \\ ${ }^{3}$ Associate Professor, Department of Anaesthesia, KFMSR, Coimbatore, Tamilnadu, India.
}

ABSTRACT

\section{BACKGROUND}

Interscalene Brachial plexus block has been utilized to provide analgesia for shoulder mobilization in frozen shoulder patients, but the associated motor blockade of the upper limb decreases the ability of the patient to do active physiotherapy. Several in-vitro studies have shown that Ropivacaine provided differential blockade with less motor weakness when compared to Bupivacaine. Hence, we designed this study to look at the motor and sensory blockade characteristics of the interscalene brachial plexus block when Ropivacaine or Bupivacaine were used as local anaesthetics.

\section{MATERIALS AND METHODS}

This randomised double blinded study was conducted in Karpagam Faculty of Medical Sciences and Research, Coimbatore, from November 2016 to November 2018. 60 patients who had frozen shoulder and who were planned for mobilization under anaesthesia were recruited. All patients were evaluated completely, and the procedure was done after obtaining informed consent. Under strict aseptic measure, interscalene catheter was introduced under the guidance of ultrasound and $20 \mathrm{ml}$ of unlabelled local anaesthetic solution containing either $0.2 \%$ Ropivacaine or $0.2 \%$ Bupivacaine were injected. After satisfying discharge criteria, patients were ambulated to the physiotherapy department where blinded physiotherapist mobilized the shoulder joint. The sensory and motor onset time, degree and duration of motor blockade, quality and duration of shoulder analgesia were recorded.

\section{RESULTS}

Both Ropivacaine and Bupivacaine provided satisfactory analgesia (VAS score $<2$ ) in all patients during shoulder mobilization. But the median degree of motor blockade ( 2 vs 2 ) and duration of motor blockade (222.4 \pm 88.4 vs $239.4 \pm 89.8$ minutes, $\mathrm{P}=0.451)$ were not less with Ropivacaine when compared to Bupivacaine. Similarly, the duration of analgesia $(259.80 \pm 82.2$ vs $273.00 \pm 89.5$ minutes, $\mathrm{p}=0.554$ ) was comparable between the groups. The sensory onset was one minute earlier in Bupivacaine when compared to Ropivacaine ( $2.2 \pm 1.2$ vs $3.2 \pm 1.9$ minutes, $\mathrm{p}=0.017)$ which was not clinically significant, but the motor onset time was comparable $(6.7 \pm 3.4$ vs $8.3 \pm 3.7$ minutes, $p=0.081)$.

\section{CONCLUSION}

We conclude that $0.2 \%$ Ropivacaine provided effective analgesia for frozen shoulder mobilization but did not provided favourable sensory motor differential blockade over Bupivacaine $0.2 \%$ for frozen shoulder management.

\section{KEY WORDS}

Ropivacaine; Bupivacaine; Interscalene; Frozen Shoulder.

HOW TO CITE THIS ARTICLE: Anguchamy NC, Natarajan V, Manian K. Effectiveness of 0.2\% ropivacaine or $0.2 \%$ bupivacaine during ultrasound guided ambulatory interscalene plexus block for frozen shoulder mobilization. J. Evolution Med. Dent. Sci. 2019;8(03):180-185, DOI: 10.14260/jemds/2019/40

\section{BACKGROUND}

Frozen shoulder is one of the commonest painful debilitating diseases of the middle and elderly population which can cause functional limitation in terms of performing basic activity of daily living. $2-3 \%$ of the general population and 2 $5 \%$ of diabetic patients are affected by the frozen shoulder of which $6-17 \%$ of them have bilateral involvement. Pathologically frozen shoulder is characterised by inflammation of the synovial lining and fibrosis of the capsule within the shoulder joint.

'Financial or Other Competing Interest': None.

Submission 14-12-2018, Peer Review 08-01-2019,

Acceptance 14-01-2019, Published 21-01-2019.

Corresponding Author:

Naveen Chandru Anguchamy,

Assistant Professor

Department of Anaesthesia

KFMSR, Coimbatore, Tamilnadu, India.

E-mail: naveenchandru1985@gmail.com

DOI: $10.14260 /$ jemds $/ 2019 / 40$
The primary treatment is focused on active and passive physiotherapy to regain the shoulder mobility at the earliest. The overall goal of treatment is to relieve pain, restore mobility and function.(1,2)

Many adjuvant therapies like oral analgesics, (3) oral and intra articular corticosteroid injection,(4) interscalene brachial plexus block ${ }^{(5,6)}$ arthroscopic and open surgical capsular release have been tried to relieve the pain and increase the patient compliance for physiotherapy. Brachial plexus block is usually given at interscalene groove to provide sensory analgesia at the shoulder joint.(7) But the accompanying motor blockade impairs the ability of the patient to do the active physiotherapy. Several invitro studies have shown that Ropivacaine provides differential blockade with less motor weakness when compared to Bupivacaine ${ }^{(8,9)}$ Hence we designed this study to look at the motor and sensory blockade characteristics of the interscalene brachial plexus block when Ropivacaine or Bupivacaine was used as local anaesthetics for frozen shoulder mobilization. 
The aim of the study is to compare the interscalene brachial plexus block characteristics in terms of-

1. Onset time for sensory and motor blockade

2. Degree and Duration of motor blockade

3. Quality of analgesia during mobilization

4. Duration of shoulder analgesia,

When bupivacaine or ropivacaine is used as local anaesthetic for frozen shoulder mobilization.

\section{MATERIALS AND METHODS}

This Randomised Double blinded study was conducted at the Karpagam faculty of Medical sciences and Research from November 2016 to November 2018. After getting informed consent, 60 consecutive patients (30 for each group) who had been posted for ultrasound guided interscalene catheter placement for frozen shoulder mobilization were recruited for the study. The total number of patients attending the ortho department with the diagnosis of frozen shoulder in a year averages around $30-40$ in our hospital which is evident from the registers. So we decided to choose 30 patients in each group leading to a total sample size of 60 . Out of 60 patients, 30 patients received $0.2 \%$ Ropivacaine and 30 patients received $0.2 \%$ Bupivacaine. In both groups there were 14 male and 16 female patients respectively. This is a double blinded study, because local anaesthetic drug $(20 \mathrm{ml}$ of $0.2 \%$ Ropivacaine or $20 \mathrm{ml}$ of $0.2 \%$ Bupivacaine) will be prepared by the anaesthesia technician and given to the anaesthesia provider as unlabelled. Here both anaesthesia provider and physiotherapist who records study parameters do not know the injected local anaesthetic, After thorough pre-anaesthetic assessment, the baseline range of motion for active and passive shoulder movements were recorded with a goniometer, the severity of pain during active movement was rated using a 10 point Visual analogue scale $(0=$ no pain, $10=$ most severe pain) by physiotherapist. After recording the baseline ROM and VAS score, patients were wheeled in to the operating room. In the operating room after establishing the standard monitors (Sp02, ECG, NIBP) and intravenous cannula, the patients were randomized in to either one of the groups by selecting a closed envelope which contain a proforma numbered from 1 to 60 . This number was passed on to an anaesthesia technician who will prepare $20 \mathrm{ml}$ of 0.2 $\%$ unlabelled local anaesthetic solution containing either bupivacaine or ropivacaine according to the computerized randomization list. After randomization procedure was done and the drug spread was confirmed by the real-time ultrasound. Drug injection time was noted as a block time. Then every 2 minutes the sensory level was assessed by an ether-soaked gauze piece on C5 dermatome and motor blockade was assessed by loss of abduction at shoulder joint. Once the motor blockade was established patient was shifted to recovery room. At the end of one-hour effectiveness of the block was assessed by Bromage scale, 0 indicating no paralysis, 1 - able to flex the elbow and move the fingers but unable to raise the extended arms, 2 - unable to flex the elbow but able to move fingers, 3 - unable to move the arm, elbow and fingers. Then the patient is subjected to physiotherapy. During the manipulation the quality of analgesia was recorded on the VAS on each manipulation manoeuvre. After manipulation all patients were discharged home on a standard oral analgesic regimen which includes paracetamol, NSAID at regular interval and a weak oral opioid such as Tab. Tramadol on demand basis. Patients were instructed to note the time when they were able to abduct the shoulder to record duration of motor blockade and perceive the shoulder pain to record the duration of analgesia from the block time. All data were recorded in the data collection proforma and entered in to the Master chart -MS Excel 2007. Statistical analysis was carried out using SPSS version 16. Parametric data was analysed with Unpaired ' $\mathrm{T}$ ' test and the nonparametric data was analysed with Mann Whitney U test. ' $\mathrm{P}$ ' value of $<0.05$ was considered significant.

\section{RESULTS}

\section{(1) Onset Time for Sensory Blockade:}

The mean onset time of sensory blockade in group B was 2.2 $\pm 1.2 \mathrm{~min}$ and in group $\mathrm{R}$ was $3.2 \pm 1.9 \mathrm{~min}$. This finding was statistically significant $(\mathrm{P}$ value $=0.017)$ but not clinically significant. The results were depicted in figure 1.

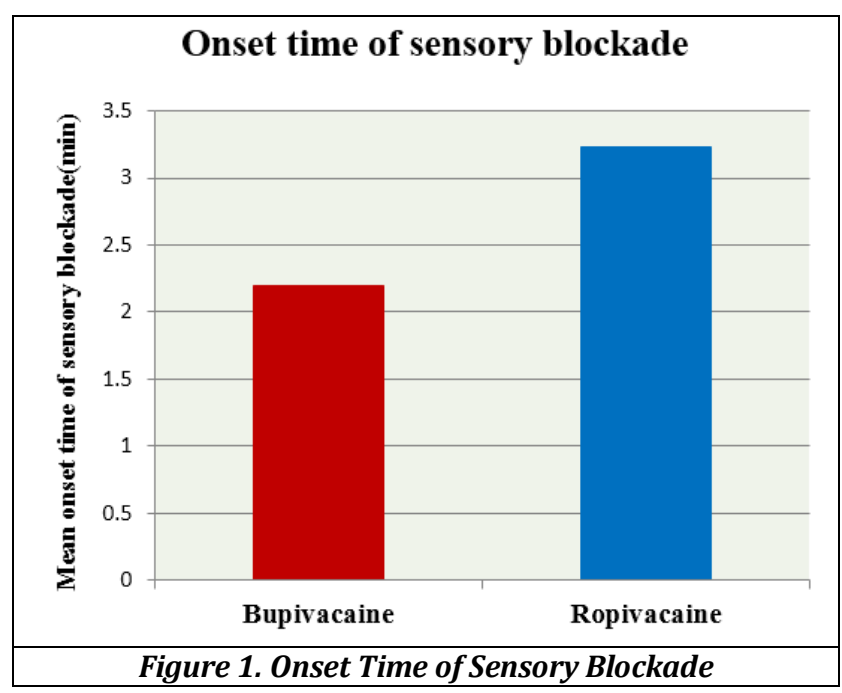

(2) Onset Time for Motor Blockade:

The mean onset time for motor blockade in group B was $6.7 \pm$ $3.4 \mathrm{~min}$ and in group $\mathrm{R}$ was $8.3 \pm 3.7 \mathrm{~min}$. When the two groups were compared, there was no significant difference in the time of onset of motor block (P value $=0.081$ ). The results were depicted in figure 2 .

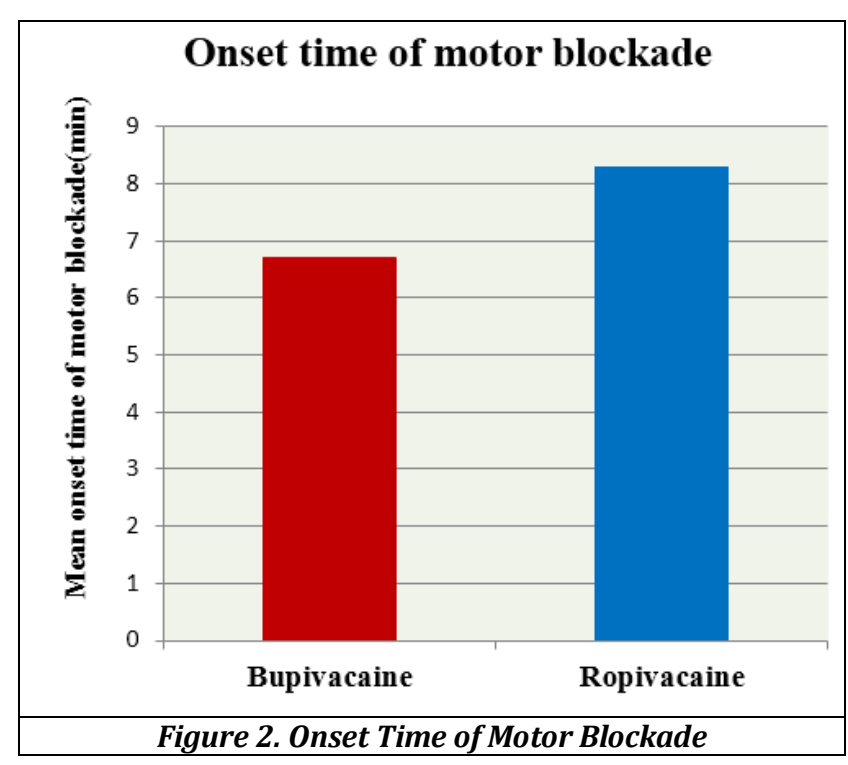




\section{(3) Degree of Motor Blockade}

The median degree of motor blockade after one hour was comparable between the two groups and was not statistically significant. The results were shown in table 1.

\begin{tabular}{|c|c|c|c|}
\hline Group & $\begin{array}{c}\text { Bupivacaine } \\
(\mathbf{N}=\mathbf{3 0})\end{array}$ & $\begin{array}{c}\text { Ropivacaine } \\
(\mathbf{N}=\mathbf{3 0})\end{array}$ & $\begin{array}{c}\text { P- } \\
\text { Value }\end{array}$ \\
\hline $\begin{array}{c}\text { Degree of Motor } \\
\text { Blockade } \\
\text { Median (Range) }\end{array}$ & $2(2-3)$ & $2(2-3)$ & 0.200 \\
\hline \multicolumn{2}{|c|}{ Table 1. Degree of Motor Blockade in Both Groups } \\
\hline
\end{tabular}

\section{(4) Quality of Analgesia}

An experienced physiotherapist who was not aware of the group allocation mobilized the shoulder joint and recorded quality of analgesia on a numerous rating scale during each mobilization manoeuvre. When the two groups were compared, there was no significant difference in the quality of analgesia. The results were represented in figure 3 .

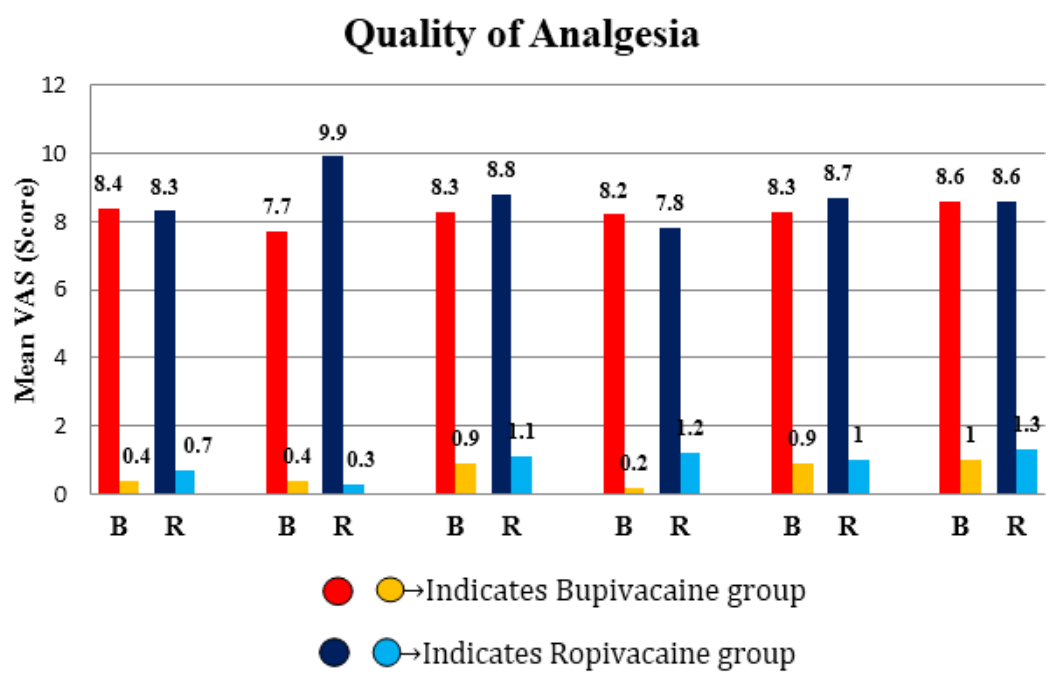

Figure 3. Quality of Analgesia Before and During Mobilization

- Respective taller bars indicate VAS score before mobilization.

- Respective smaller bars indicate VAS score during mobilization.

(5) Range of Motion Before and After Mobilization

An experienced physiotherapist has mobilized the shoulder joint after interscalene plexus block who was not aware of the group allocation has recorded the range of motion during each manipulation manoeuvre. There was significant improvement in the range of motion in both the groups after the end of mobilization, but it was not statistically different between the groups. The results were depicted in figure 4.

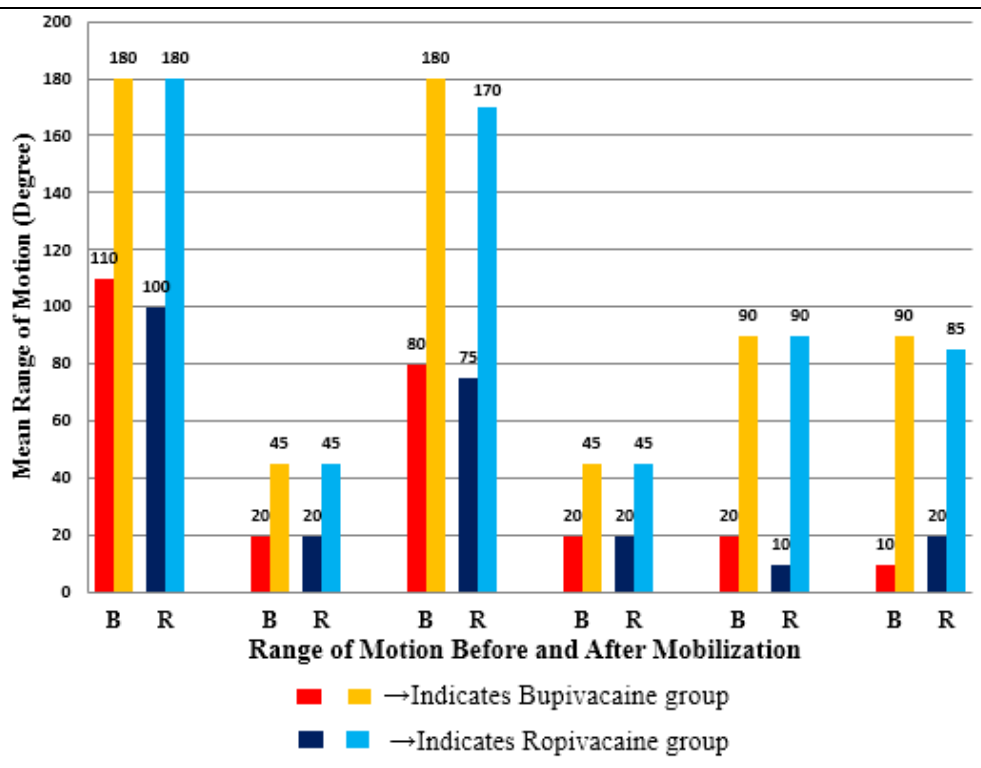

Figure 4. Range of Shoulder Motion Before and After Mobilization

- $\quad$ Respective smaller bars indicate ROM before mobilization.

- Respective taller bars indicate ROM after mobilization. 


\section{(6) Duration of Motor Blockade}

The mean duration of motor blockade in group B was $239.4 \pm$ $89.8 \mathrm{~min}$ and in group $\mathrm{R}$ was $222.40 \pm 88.4 \mathrm{~min}$. When the two groups were compared, there was no significant difference in the duration of motor blockade $(\mathrm{P}$ value $=$ 0.451). The results were depicted in figure 5 .

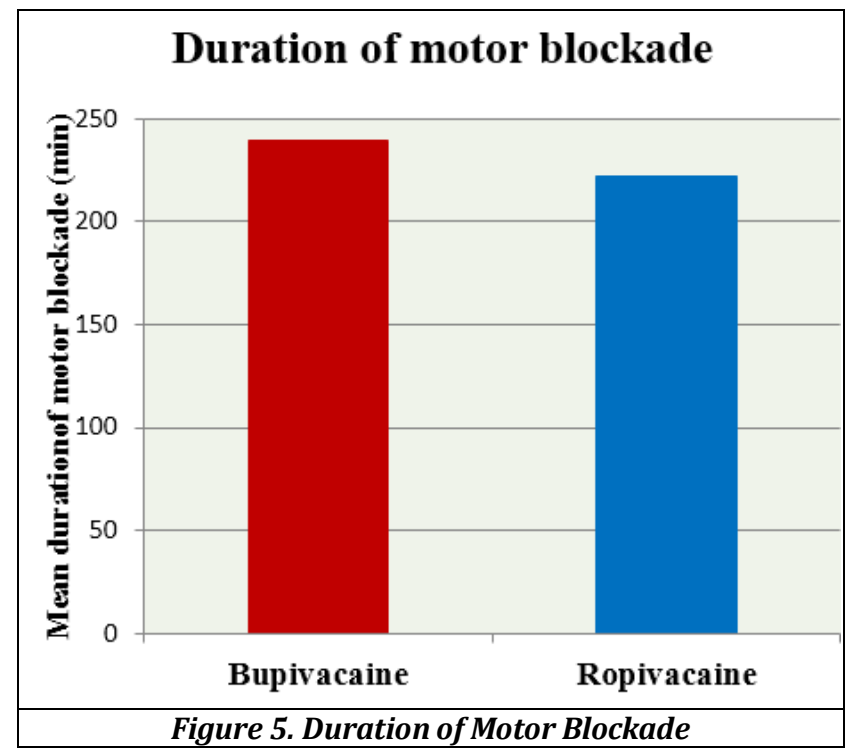

\section{(7) Duration of Analgesia}

The mean duration of analgesia in group $B$ was $273.00 \pm 89.5$ min and in group $\mathrm{R}$ was $259.80 \pm 82.2 \mathrm{~min}$. When the two groups were compared, there was no significant difference in the duration of analgesia $(\mathrm{P}$ value $=0.554)$. The results were depicted in figure 6 .

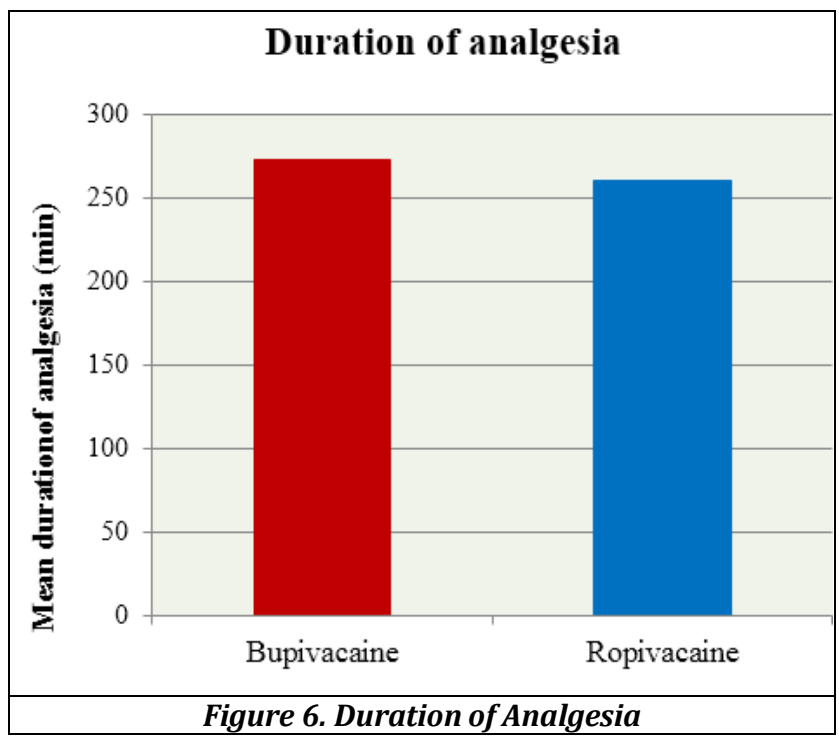

\section{DISCUSSION}

In this randomized double blinded study, we recruited 60 patients who had frozen shoulder willing to undergo physiotherapy after Interscalene brachial plexus block and divided them randomly into two groups. Patients in group- $R$ received $20 \mathrm{ml}$ of $0.2 \%$ ropivacaine and patients in group- $B$ received $20 \mathrm{ml}$ of $0.2 \%$ bupivacaine for Interscalene brachial plexus block. We observed for sensory onset time, motor onset time, degree of motor blockade, duration of analgesia, quality of analgesia and duration of motor blockade. We analysed the parametric data using unpaired-' $t$ ' test and nonparametric data using Mann-Whitney ' $U$ ' test.

Brachial plexus block for shoulder mobilization has been increasingly used because it provides ideal manipulation conditions like GA and prolonged analgesia after the procedure. $(5,6,7)$ But in case of severe stiffness full range of motion cannot be attained in one sitting and patients needed more than one episode of mobilization and prolonged analgesia to facilitate active physiotherapy during recovery phase. The goal of frozen shoulder treatment can be achieved by providing effective analgesia for active and passive physiotherapy. Yilmazlar et al(6) mobilized three patients under Interscalene block and administered continuous catheter analgesia for 21 days to facilitate physiotherapy. All three patients were treated as in-patients. They concluded that continuous ISB provided sufficient analgesia and contributed to the recovery of shoulder function, but the ambulatory application of this technique has to be evaluated prospectively.

The analgesic efficacy of ropivacaine and bupivacaine had been extensively studied in the settings of labour analgesia.(10,11) Casati et al(12) studied the minimum local anaesthetic volume blocking the femoral nerve in $50 \%$ of cases with $0.5 \%$ Bupivacaine or $0.5 \%$ Ropivacaine and found that the volume needed for successful block was $14 \pm 2 \mathrm{ml}$ in the Ropivacaine group and $15 \pm 2 \mathrm{ml}$ in the Bupivacaine to produce equal effect. Similarly Hickey et al(13) compared the effectiveness of $0.25 \%$ ropivacaine and $0.25 \%$ bupivacaine in 44 patients receiving a subclavian perivascular brachial plexus block and found that the block characteristics were comparable between the two drugs.

The sensory motor differential blockade of Ropivacaine was very well demonstrated in spinal and epidural anaesthesia.(8,9) But the same results were not consistently reproduced in the peripheral nerve blocks.(13,14)

Introduction of ultrasound technology in regional anaesthesia enabled the clinician to deposit the local anaesthetic more close to the nerves which improved the efficacy of the block and decreased the complication rate.(15,16) Hence in our study we did all the ISB on ambulatory basis using $20 \mathrm{ml}$ of $0.2 \%$ ropivacaine and $0.2 \%$ bupivacaine.

\section{Onset of Sensory Blockade}

In our study the mean onset time of sensory blockade in group B was $2.2 \pm 1.2 \mathrm{~min}$. And in group $\mathrm{R}$ was $3.2 \pm 1.9 \mathrm{~min}$. This finding was statistically significant ( $\mathrm{p}$-value $=0.017$ ) but not clinically significant. In the study conducted by McCrae et al the onset for pain relief after first dose of $0.5 \%$ bupivacaine was $12 \mathrm{~min}$. and $18 \mathrm{~min}$ in $0.5 \%$ ropivacaine $(\mathrm{P}$-value $=<$ 0.05). When given for extradural analgesia during labour. In the study conducted by Wideside et al (17) the onset time for sensory block after $3 \mathrm{ml}$ of intrathecal $0.5 \%$ ropivacaine was $5 \mathrm{~min}$ and for that of $3 \mathrm{ml}$ of $0.5 \%$ bupivacaine was $2 \mathrm{~min}(\mathrm{p}$ value $=0.0046$ ) they attributed the difference to baricity of the solutions used. Bupivacaine being more potent than ropivacaine at equal concentration provided earlier onset of sensory block. In the study conducted by Hickey et al the mean onset time for analgesia for ropivacaine $0.25 \%$ was $19.2 \pm 22.2$ and for bupivacaine $0.25 \%$ was $11.5 \pm 14.0$ at C5 dermatome when given for brachial plexus block. We 
observed earlier onset of analgesia when compared to this study which could be because of USG guided block used in our study.

\section{Onset of Motor Blockade}

In our study mean onset time for motor blockade in group-B was $6.7 \pm 3.4$ and in group- $R$ was $8.3 \pm 3.7 \mathrm{~min}$. when the two groups were compared, there was no significant difference in the time of onset of motor block ( $p$-value $=0.08$ ). In the study conducted by Hickey et al the onset time for motor blockade was $12.2 \pm 8.3 \mathrm{~min}$ in $0.25 \%$ ropivacaine group and $14.8 \pm$ 13.4 in $0.25 \%$ bupivacaine group when used in brachial plexus block. The difference was not statistically significantly ( $\mathrm{p}$-value $>0.05$ ).

\section{Degree of Motor Blockade}

In our study degree of motor blockade was 2-3 in both the groups with p-value of 0.200 . In the study conducted by McCrae et al, to compare $0.5 \%$ bupivacaine and $0.5 \%$ ropivacaine for labour analgesia, the degree of motor blockade was assessed by Axelsson's quantitative method during isometric contraction. They found that 12 out of 20 patients in ropivacaine group and 11 out 20 patients in bupivacaine group come under degree 1 motor blockade. The difference was not statistically significant. One patient in each group was under grade 2 motor blockade and none of the patients in either group had severe motor blockade. They used a higher concentration of drug and a different assessment tool to assess the motor blockade. In our study we assessed the degree of motor blockade after one hour of drug injection.

\section{Quality of Analgesia}

In our study the mean baseline VAS scores ranged between $7.7 \& 8.6 \mathrm{~mm}$ in bupivacaine group and ranged between 7.8 \& $9.9 \mathrm{~mm}$ in ropivacaine group. After block the mean VAS score ranged between 0.2 and $1 \mathrm{~mm}$ in bupivacaine group, and ranged between $0.3 \& 1.3 \mathrm{~mm}$ in ropivacaine group. There was significant decrease in VAS score in both the groups after block, but the difference between the groups was not statistically significant. In the study conducted by McCrae et al, quality of analgesia was evaluated using $100 \mathrm{~mm}$ VAS score before and after the epidural block. The mean VAS score before the drug dose were $84 \mathrm{~mm}$ in ropivacaine group and $69.5 \mathrm{~mm}$ in bupivacaine group and the mean VAS score 60 minutes after the block were $11.7 \mathrm{~mm}$ in ropivacaine group and $12.4 \mathrm{~mm}$ in bupivacaine group. This was comparable with the values achieved in our study.

\section{Duration of Analgesia and Motor Blockade}

In our study mean duration of analgesia in group-B $273.00 \pm$ $89.5 \mathrm{~min}$ and in group- $\mathrm{R}$ was $259.8 \pm 82.2 \mathrm{~min}$. The mean duration of motor blockade on group-B was $239.4 \pm 89.8 \mathrm{~min}$ and group-R was $222.4 \pm 88.4 \mathrm{~min}$. There was no significant difference between the two groups in duration of analgesia ( $p$-value $>0.05$ ) and duration of motor blockade $(p=0.451)$. In the study conducted by Hickey et al the duration of analgesia in shoulder was $10.7 \pm 2.6 \mathrm{hrs}$. in ropivacaine group and 13.0 $\pm 4.7 \mathrm{hrs}$. in bupivacaine group. The duration of motor blockade was $8.6 \pm 1.8 \mathrm{hrs}$. in ropivacaine group and $11.4 \pm$ 5.6 in bupivacaine group ( $p$-value $>0.05$ ). The prolonged duration of analgesia and motor blockade in their study could be attributed to higher volume of drug used ( $40 \mathrm{ml})$ when compare to that in our study $(20 \mathrm{ml})$.

\section{CONCLUSION}

Based on the results and the methodology employed, we have concluded that ropivacaine $0.2 \%$ provided effective analgesia for shoulder mobilization, but produced similar degree and duration of motor blockade when compared to bupivacaine $0.2 \%$ during the interscalene brachial plexus block for frozen shoulder mobilization.

\section{REFERENCES}

[1] Harrast MA, Rao AG. The stiff shoulder. Phys Med Rehabil Clin N Am 2004;15(3):v, 557-73.

[2] Anton HA. Frozen shoulder. Can Fam Physician 1993;39:1773-8.

[3] Buchbinder R, Hoving JL, Green S, et al. Short course prednisolone for adhesive capsulitis (frozen shoulder or stiff painful shoulder): a randomised, double blind, placebo controlled trial. Ann Rheum Dis 2004;63(11):1460-9.

[4] Ryans I, Montgomery A, Galway R, et al. A randomized controlled trial of intra-articular triamcinolone and/or physiotherapy in shoulder capsulitis. Rheumatol (Oxford) 2005;44(4):529-35.

[5] Roubal PJ, Dobritt D, Placzek JD. Glenohumeral gliding manipulation following interscalene brachial plexus block in patients with adhesive capsulitis. J Orthop Sports Phys Ther 1996;24(2):66-77.

[6] Yilmazlar A, Türker G, Atici T, et al. Functional results of conservative therapy accompanied by interscalane brachial plexus block and patient-controlled analgesia in cases with frozen shoulder. Acta Orthop Traumatol Turc 2010;44(2):105-10.

[7] Mariano ER, Afra R, Loland VJ, et al. Continuous interscalene brachial plexus block via an ultrasoundguided posterior approach: a randomized, triplemasked, placebo-controlled study. Anesth Analg 2009;108(5):1688-94.

[8] Badner NH, Reid D, Sullivan P, et al. Continuous epidural infusion of ropivacaine for the prevention of postoperative pain after major orthopaedic surgery: a dose-finding study. Can J Anaesth 1996;43(1):17-22.

[9] Kallio H, Snall EV, Kero MP, et al. A comparison of intrathecal plain solutions containing ropivacaine 20 or $15 \mathrm{mg}$ versus bupivacaine $10 \mathrm{mg}$. Anesth Analg 2004;99(3):713-7.

[10] Stienstra R, Jonker TA, Bourdrez P, et al. Ropivacaine $0.25 \%$ versus bupivacaine $0.25 \%$ for continuous epidural analgesia in labor: a double-blind comparison. Anesth Analg 1995;80(2):285-9.

[11] McCrae AF, Jozwiak H, McClure JH. Comparison of ropivacaine and bupivacaine in extradural analgesia for the relief of pain in labour. $\mathrm{Br} J$ Anaesth 1995;74(3):261-5.

[12] Casati A, Fanelli G, Magistris L, et al. Minimum local anesthetic volume blocking the femoral nerve in $50 \%$ of cases: a double-blinded comparison between $0.5 \%$ ropivacaine and $0.5 \%$ bupivacaine. Anesth Analg 2001;92(1):205-8. 
[13] Hickey R, Rowley CL, Candido KD, et al. A comparative study of $0.25 \%$ ropivacaine and $0.25 \%$ bupivacaine for brachial plexus block. Anesth Analg 1992;75(4):602-6.

[14] McNamee DA, McClelland AM, Scott S, et al. Spinal anaesthesia: comparison of plain ropivacaine $5 \mathrm{mg}$ $\mathrm{ml}(-1)$ with bupivacaine $5 \mathrm{mg} \mathrm{ml}(-1)$ for major orthopaedic surgery. Br J Anaesth 2002;89(5):702-6.

[15] Thomas LC, Graham SK, Osteen KD, et al. Comparison of ultrasound and nerve stimulation techniques for interscalene brachial plexus block for shoulder surgery in a residency training environment: a randomized, controlled, observer-blinded trial. Ochsner J 2011;11(3):246-52.
[16] Danelli G, Bonarelli S, Tognú A, et al. Prospective randomized comparison of ultrasound-guided and neurostimulation techniques for continuous interscalene brachial plexus block in patients undergoing coracoacromial ligament repair. $\mathrm{Br} \mathrm{J}$ Anaesth 2012;108(6):1006-10.

[17] Whiteside JB, Burke D, Wildsmith JA. Comparison of ropivacaine $0.5 \%$ (in glucose $5 \%$ ) with bupivacaine $0.5 \%$ (in glucose $8 \%$ ) for spinal anaesthesia for elective surgery. Br J Anaesth 2003;90(3):304-8. 